\title{
Student Research Opportunities in Industry
}

\author{
Raymond E. Thompson, Brenda A. Morton \\ Purdue University
}

\begin{abstract}
In 1995 the Aviation Technology (AT) Industrial Advisory Committee suggested the need to provide additional communication, team building, presentation, and business skills for AT students. In response, the AT department began working with several air carriers doing applied research in the areas of human factors and safety. Projects include shift turnover communication, ramp safety, lifting ergonomics, flow mapping, and error prediction. Each project is under the leadership of a student team leader with additional students working in support. The teams are paired with a faculty member.
\end{abstract}

The main goal of these projects is for students to obtain real experience, enhance their leadership and team skills, and improve presentation skills. Students coordinate all activities from designing metrics to arranging for travel. This has created a pipeline of highly qualified students with enhanced skills beyond what the classroom can provide. These students are highly recruited upon graduation. The AT department acts as a partner, not a consultant to the industrial participant. Solutions are devised, tested, and implemented by the students and the air carrier works in conjunction with the students during this process. As the project evolves, the AT department withdraws to an advisory position leaving the air carrier with something they helped devise and continue with on their own.

The benefits to the students have been tremendous. Numerous papers co-authored with the faculty have been presented at significant conferences worldwide. Students work with all levels of personnel including upper management and vice presidents making presentations of results. Over 50 internships supporting these projects have resulted during 2000 alone. Establishing applied industry research partnership opportunities has been a tremendous success for all involved, especially the students. The exposure and experience gained is invaluable in preparing for their upcoming careers in the aerospace and air transport industries.

\section{Introduction}

The goal of the Applied Research Program is provide real life educational experiences and applied research opportunities through a linkage between industry and the university. The research is results oriented with Purdue working with industry to provide practical solutions for improved safety, efficiency, and profitability. The program is open to any qualified student at Purdue. Students must participate in several orientation programs and complete coursework in 
aviation infrastructure and human factors. Students must maintain a 2.5 GPA and participation may be restricted if their grades suffer. Students work in teams under the mentorship of supervising faculty.

\section{Program Structure}

The program consists of a faculty Oversight Committee, graduate assistant, Project and Support Teams. The role of the Oversight Committee is to determine which projects to undertake, monitor student participation, mentor students, and assist with the student-industry interface. At present, there are four faculty members from the Aviation and Communication departments participating. Each faculty member is assigned to work specifically with a project team and in general with all projects.

The role of the graduate assistant is important due to the nature of his or her placement in the structure of the program. The research assistant usually has the most experience with the projects. Generally the student has been a research team member as well as a successful project leader. The graduate assistant acts as a mentor for the other members and leaders. The graduate assistant runs the oversight committee meetings and acts as a liaison between the committee and research teams. Part of the duties of the graduate assistant are to ensure the research teams have the resources, information, training, and help the leaders organize their projects. The role of the graduate assistant is to set up and ensure accountability with proper roles and responsibilities of the team members and project leaders. One technique is starting to use an interactive website for members to post meeting minutes, project timelines, group presentations and a general calendar for all to see when teams schedules are. This is a tremendous help in sharing knowledge as well as being able to track progress.

In conjunction with the faculty advisors, the graduate assistant mentors the research leaders into eventually becoming graduate assistants themselves. Along with responsibilities to the individuals themselves, the grad assistant holds regular meetings with the project leaders to ensure the sharing of information. Such discussions include problems related to the project and how others have handle similar situations, and issues regarding member participation and group motivation. Monthly social gatherings with all project leaders and oversight committee members' help in accountability of not only the leaders, but the faculty involved.

Students may participate in two ways. First, students may work on project team that directly interfaces with the industrial partner. As a research team member, the student chooses his or her level of involvement with a project based upon time availability and interest. Each team travels to industry locations and conducts studies, working closely with industry partners and employees to identify and analyze the problem. The team assesses potential causes and formulates solutions for test implementation. Team Leader's establish project timelines and milestone presentations, which are then given by the team members to the industry partner's upper management. Once implementation occurs, the team establishes follow-up procedures of the test model. The second method is to work on one of several support teams. These include Metrics, Communications, Error Management, and Work Process Teams. These groups provide support to the project teams and often work on various components of all projects. Many students participate on both levels. 
Currently, over forty students are taking advantage of the applied research program and its benefits. Team members are educated and trained in human factors, error management, how to make proper observations and holding focus groups and personal interviews. Project Leaders learn how to conduct meetings, make project timelines, work with industry partners to ensure accomplishment, and develop their team members. The structure of the applied research program is that of an organization, with major support in place from the graduate assistant and the oversight committee.

\section{Research Projects}

Past research projects include Flight Attendant Lost-time Injuries, including travel to Paris \& London; Shift-Turnover with Line \& Hangar Maintenance Technicians; Ground Damage, and basic Human Factors \& Error Management training development. The research projects are not limited to any one carrier or geographic region, as the teams have worked from the east coast to the west coast, Hawaiian Islands, Europe and Asia. Currently the research program is involved with four research projects regarding improving Ground Damage and Lost Time Injuries with three major commercial air carriers and a cargo operator.

The research methods typically used in evaluation of the industry partner are quite labor intensive. A research team will generally begin reviewing and analyzing historical error data, followed by observations and job shadowing. Once the team has an understanding from their perspective they must gain the knowledge of the employees themselves. Employee perception surveys are done as well as one-on-one interviews. Focus groups are also held in order to help understand the culture of the organization as a whole. Student participants have analyzed at least 5 historical databases, received more than 2800 responses from surveys, logged over 11,000 hours of job shadowing, held over 300 interviews, and well over 23 focus groups. Considering that students are not paid by the industry partner for their efforts, the amount of work performed is quite impressive.

To ensure that all eligible students can participate, the industry partner supplies hotel accommodations and travel is furnished for the students to make station visits. Per Diem is also furnished for reimbursement of meals. There have also been on occasion, pizzas or other college student favorites bought by industry partners while in a working session.

\section{Student Benefits}

Although student participants are not paid, the rewards for their efforts are invaluable. Students gain practical experience along with opportunities to gain a competitive edge over their peers. Many students who are enrolled in the Purdue University Aviation Technology program have not had any work experience in the aviation industry yet. The research projects give the student the opportunity to interact with mechanics, ramp servicemen, customer service representatives, cabin servicemen, fuelers, pilots, flight attendants and others. Some of the team members have even assisted in push back, ground handling, and taxing of 777's, 747's, 767's, etc. Being able to work in the "live" environment that they are studying allows the student the chance to use the knowledge they have learned. The exposure to the world is something sitting in a classroom 
can't offer. Working from the "ground up" the students interact with frontline employees to Station Managers, all the way to Vice Presidents.

Once the research team members have formulated the solution and are ready for implementation, they then make presentations to the industry partner's upper management. Unlike presentations in classrooms, student team members make PowerPoint presentations in executive conference rooms, and must gain approval of Managers and VP's. These plans often require the industrial partner to commit financial resources and personnel. Presentations must include the justification of these resources. Project timelines are such that milestone presentations are crucial for the success of the research project. Here is the opportunity to learn the inner workings of company politics. Students start to understand what is important to an organization and what is not. A hard lesson is learned when having to appease to particular members of management while at the same time learning to not disappoint someone else.

Research team members enhance their basic skills from project participation. From improving communication and presentation skills, to developing advanced teamwork appreciation, students are able to grow at a much faster and comprehensive rate than sitting in a classroom. Project Leaders also learn project management skills, and get first hand experience at managing a group of people as well as the individual themselves. Project Leaders mentor potential team members into taking future leadership roles. They also are able to develop communication skills with their "manager" or faculty advisor. Because the Applied Research Program is run much like an organization with the Oversight Committee as "Upper Management", Project Leaders experience managing manpower, and understanding where to obtain their resources. They act as a liaison between their industry partner's needs and their team's abilities to supply those needs.

Because of the exposure to industry partners, students have a competitive edge sometimes over their peers. Many students having participated in a research project have been hired into impressive positions within the companies they have worked with. Salaries are often higher due to the exposure and work experience with that particular company. Working with industry partners also gives an advantage of knowing a company better than just reading about them. However, as with internship and Co-op programs, the experience can occasionally leave a bad impression of the student on the company.

Students must understand the sensitive nature of the aviation business. By working with an industry partner, research team members are exposing themselves and their work habits. Although the potential for something to go wrong throughout the project is protected by the faculty involvement, the potential is still there. Industry partners understand they are working with college students, but students still need to respect the individuals who they're dealing with. The possibility of being denied future employment because of a poor relationship in the research project is highly unlikely, but should not be disregarded.

Aside from the rare possibility of developing a poor relationship with an industry partner, there are few disadvantages from the student perspective. The biggest student concern is time. Time is of the essence for most college students. In addition to attending regular classes and participating in extra-curricular activities, most students have regular part-time employment. This can put a damper on participation with the research projects. Some projects require 
observations to be performed during third shift, making for extremely late nights. Other projects require travel out of town and for several days, requiring students to balance missing classes and making up homework or exams. However each student decides how much he or she wants or can participate. Most students find time to work with industry partners due to the tremendous gains.

V. Summary

The Applied Research Program has been a tremendous success. Placement of student participants upon graduation has been nearly $100 \%$. Industry feedback indicates that these students are highly prepared to move into positions within industry that are several levels above that available for most graduates. Students find these projects very exciting and motivating. The additional skills and confidence they achieve are readily apparent and of great value to industry.

Numerous papers co-authored with the faculty have been presented at significant conferences worldwide. Students work with all levels of personnel including upper management and vice presidents making presentations of results. Over 50 internships supporting these projects have resulted during 2000 alone. Establishing applied industry research partnership opportunities has been a tremendous success for all involved, especially the students. The exposure and experience gained is invaluable in preparing for their upcoming careers in the aerospace and air transport industries.

This program continues to grow and evolve. Although time consuming on everyone's part, the benefits to the student make is a worthwhile expenditure of time. In addition, the public relation value and increasing industry interaction within the AT department have provided benefits to all students. As the program expands, the next step is to attract student and faculty participants from other institutions. The process to accomplish this is being developed at this time.

\section{RAYMOND E. THOMPSON}

Raymond E. Thompson is Associate Professor of Aviation Technology at Purdue University in West Lafayette. Prof. Thompson founded the AOT Advanced Composite Laboratory and coordinates student services within the department. His current research includes assessment, technology in the classroom, distance education, and aviation human factors.

\section{BRENDA A. MORTON}

Brenda A. Morton is a master degree student in Technology at Purdue University in West Lafayette. Ms. Morton graduated with a BS in Aviation Administration in 1999 and currently is the graduate assistant for the Applied Research Program in Aviation Technology. 